\title{
The Responses of Drug Abuse Treatment Organizations to Financial Adversity: A Partial Test of the Threat-Rigidity Thesis
}

\author{
Thomas D'Aunno \\ The University of Michigan \\ Robert I. Sutton \\ Stanford University
}

\begin{abstract}
This article derives hypotheses from the threat-rigidity model about organizational responses to financial adversity. These hypotheses are tested in a national sample of 72 randomly selected drug abuse treatment organizations. We propose that decreasing funding levels and numbers of funding sources will be associated with four classes of rigidities in organizations: (a) restriction in information processing (rigid use of existing organizational procedures), (b) constriction of control (less participative decision making), (c) conservation of resources (work force reduction), and (d) competition among members. The threat-rigidity thesis is supported by findings that decreases in total budgets are associated with rigid use of existing procedures, work force reduction, and competition among organization members. Further, decreases in number of funding sources are associated with less participative decision making, work force reduction, and more competition among members.
\end{abstract}

The notion that financial threat and adversity lead to rigid responses by organizations is a persistent theme in the organizational studies literature. Staw, Sandelands, and Dutton (1981) presented the most complete and well-integrated model for understanding how potentially negative or harmful circumstances, such as financial adversity, can provoke rigid responses in organizations including restriction in information processing, constriction in control, and conservation of resources $(516)^{1}$.

Preparation of this paper was supported by Grant No. DA03272 from the National Institute on Drug Abuse.

We wish to thank Jane Dutton, Leonard Greenhalgh, and Richard H. Price for their helpful comments on this paper.

Address all correspondence to Thomas D'Aunno, Institute for Social Research, Survey Research Center, The University of Michigan, Ann Arbor, MI 48106.

'Staw, Sandelands, and Dutton (1981) define "threat" as "an environmental event that has impending negative or harmful consequences for the entity" (502). Yet, many of the examples of threats they discuss already entail the onset of negative or harmful consequences for organizations and their members. That is, the threatening events are no longer impending but have occurred. Thus, given that the financial conditions we focus on have already occurred, we prefer to use the term "financial adversity" rather than "financial threat."

Copyright 1992 by the Southern Management Association 0149-2063/92/\$2.00. 
Elements of their model are consistent with research on organizations that face financial threats. For example, restriction in information processing is supported by Cameron, Whetten, and Kim's (1987b) findings that resistance to change and lack of innovation were more pronounced in colleges and universities with stable or declining revenues than those with growing revenues. Constriction of control is suggested by Pfeffer and Leblebici's (1973) finding that competitive organizational environments were associated with centralization in manufacturing firms. Conservation of resources through use of work force reduction was evident in Warren's (1984) participant-observer study of a financial crisis at Antioch University.

Gladstein and Reilly (1985) used a management simulation game to test the threat-rigidity thesis. They used 24 groups comprising $128 \mathrm{MBAs}$, who played a simulation game under conditions of high and low threat. Threat was simulated by a combination of time pressure and negative financial consequences. They found that high threat was associated with constriction of information processing, but not with constriction of control.

Fragments of the model are supported by prior field studies and Gladstein and Reilly's simulation game provides a partial test. But our review of the literature indicates that no field study has explicitly tested the model of organizational response to threat developed by Staw and his colleagues. This study provides the first explicit field test of this model to date through the use of a representative national sample of 72 drug abuse treatment organizations. Our test of the threatrigidity thesis is partial rather than complete because we could neither examine all of the outcomes predicted by Staw and his colleagues nor could we examine the intervening mechanisms hypothesized to bring about such outcomes. This study tests two key hypotheses derived from the perspective developed by Staw and his colleagues, and from related conceptual work on shrinking organizational financial resources (Sutton \& D'Aunno, 1989), about the relationship between financial adversity in drug abuse treatment organizations and rigidities in their responses.

\section{Adverse Financial Circumstances as Threats}

Money is one of the most flexible, universally exchangeable (Foa, 1971), and symbolically powerful resources. Decreases in an organization's funding threaten leaders and other members ${ }^{2}$. Funding decreases may be interpreted by key exchange partners as a sign of managerial incompetence and organizational ineffectiveness. As a result, leaders are likely to be blamed and replaced when financial

\footnotetext{
${ }^{2}$ We focus here on changes in financial circumstances as threats rather than the absolute level of financial resources and the absolute number of funding sources. We do so because, whether the absolute levels are large or small, organizations that have a given level of financial resources or a given number of funding resources as enduring characteristics will have had time to adjust their organization structures and jobs to those constraints. Members of an organization that has had a $\$ 300,000.00$ budget and the same two funding sources for the past 7 years are unlikely to experience endemic and prolonged anxiety because they have a smaller budget and fewer funding sources compared to other similar organizations. Thus, absolute indicators of financial circumstances may be best viewed as measures of the scale of operations rather than of the presence or absence of threat. In contrast, the loss of resources and of key exchange partners are more likely to be construed as threats because such new information signals that, rather than a continuation of the status quo or an improvement in the quality of organizational life, changes may take place that are negative or harmful to leaders and other members.
} 
performance is poor (Meindl, Ehrlich, \& Dukerich, 1985; Pfeffer \& Salancik, 1978). Further, leaders are socialized to believe that they deserve the lion's share of blame (and credit) for organizational financial performance. And, as Whetten (1980a) suggests, such beliefs are reinforced by a culture in which association with financial difficulties is practically a national taboo.

Shrinking financial resources also threaten members at lower hierarchical levels. Financial difficulties can lead to cost-cutting measures including pay cuts, shortened work weeks, demotions, involuntary transfers, forced early retirement, and most threatening, permanent layoff. Cameron and his colleagues (1987a) suggest that members at lower levels may, in fact, be more threatened by budget cuts than top managers because of the tendency (Freeman \& Hannan, 1975) for declining organizations to reduce the direct work force more quickly than the number of administrators.

Conversely, increased financial resources signal the absence of threat. The American culture emphasizes that growth equals progress (Whetten, 1980b). Financial growth is perhaps the most valued form of progress in our culture. Observers - including organizational exchange partners - attribute successful financial performance to an organization's leaders (Meindl et al., 1985). As a result, leaders' tenure is typically longer in financially successful than in financially troubled organizations (Pfeffer \& Salancik, 1978). Lower-level employees of such successful organizations may also have greater job security and be more likely to garner rewards such as pay increases.

These arguments suggest that revenue decreases are the most threatening changes in an organization's financial circumstances. But even if revenue is unchanged, a decrease in the number of funding sources that an organization depends on is also threatening. Such losses increase an organization's dependence on remaining funding sources. Heightened dependence on fewer sources is threatening because it increases the power of external groups over the organization and its managers (Jacobs, 1974; Pfeffer \& Salancik, 1978). Moreover, leaders who cannot maintain the participation of suppliers of funds may lose credibility with other exchange partners. In contrast, organizations that experience an increase in the number of funding sources are less dependent on any single source and thus less vulnerable if any given funding source makes unreasonable demands or withdraws support.

\section{Organizational Responses to Financial Adversity}

If organizations face financial adversity such as loss of funding and funding sources, then according to Staw and his colleagues, three kinds of rigidity will be observed within the organization: restriction of information processing; constriction of control; and conservation of resources. Moreover, we extend their logic to argue that financial adversity will be associated with a fourth kind of rigidity in organizations: competition among members.

First, restriction in information processing is evident when there is reliance on prior knowledge, overload of communication channels, and reduction in communication complexity. This study examined an indicator of reliance on prior knowledge: rigid use of existing procedures. The anxiety and arousal evoked by finan- 
cial adversity may cause leaders and other members to narrow their field of attention and lower their sensitivity to peripheral cues (Gladstein \& Reilly, 1985; Staw et al., 1981). In turn, they will have greater difficulty processing new or complex information. The result is that people under threat or adversity may rely heavily on past experience or prior knowledge regardless of whether or not existing routines are appropriate for dealing with the current threat (Starbuck, Greve, \& Hedberg, 1978; Zajonc, 1965).

Case studies including Hirschhorn's work on budget cutbacks in public agencies (1983), Nystrom and Starbuck's (1984) analysis of financially troubled firms, and Sutton, Eisenhardt, and Jucker's (1986) description of the collapse of the Atari Corporation suggest that shrinking financial resources cause leaders and other members to cling to well-learned responses. This link is also suggested in a quantitative study by Cameron and his colleagues (1987a; 1987b) of 334 colleges and universities, which found that shrinking financial resources were associated with resistance to change, curtailment of innovation, and lack of long-term planning.

Second, Staw and his colleagues propose that threat and adversity lead to constriction of control by a smaller number of decision makers. This study examined lack of participation in decision making as an indicator of constricted, centralized control. Decision makers under threat attempt to enhance their control so that subordinates will act in concert with their wishes. Further, because anxiety interferes with the ability to process uncertain information, leaders may limit participation in decision making because it eliminates uncertainty about decision outcomes. Anxiety also hampers peoples' ability to remember and use information that is incongruent with their expectations. Because limiting participation includes a reduction in the number of decision participants, it is a means that leaders can use to avoid interacting with people who disagree with their opinions (Janis, 1982).

The hypothesis that participation in decision making decreases under financial adversity has not, however, been consistently supported. Rubin's (1977) case studies of five universities facing financial adversity and case studies of financially troubled firms by Starbuck et al. (1978) and Sutton et al. (1986) indicated that leaders responded to threat by centralizing decision making. There is also limited quantitative evidence for this link. Pfeffer and Leblebici (1973) found that the combination of greater market competition and more rapid environmental change was associated with limited participation in decision making. Conversely, Gladstein and Reilly's (1985) simulation found no significant relationship between level of threat and centralization. Similarly, Cameron and his colleagues (1987a; 1987b) found no significant differences in centralization between institutions of higher learning that had declining, stagnant, or increasing revenues.

Third, conservation of resources may occur in response to financial adversity. Staw and his colleagues imply that such concern with efficiency may be manifested in cost cutting. Literature on turnaround strategies also indicates that conservation of resources is among the most frequent responses by firms facing financial difficulties (e.g., Hambrick \& Schecter, 1983). Organizations may cut costs by shrinking the work force, reducing the hours worked by employees, lowering pay, demoting employees, and encouraging employees to take leaves of ab- 
sence (Perry, 1986). This study examined work force reduction as an indicator of cost-cutting.

Fourth, extending the logic that Staw and his colleagues used to explain group responses to threat, competition among organization members may increase in response to financial adversity. Competition is a rigid response to adversity to the extent that it reduces the cooperation needed for collective action, which is required to bring about organizational change. Faced with scarce or declining resources, organization members may try to get ahead at each other's expense, thus making it difficult for them to develop and implement strategies to protect the organization's interests as a whole. We examined competition among organization members in this study.

In an extensive review of the literature, Thomas (1976) concluded that competition and conflict among organization members increase in times of scarce or diminished resources. Whetten (1980b: 369) also proposed that interpersonal conflict is a consequence of a declining organizational resource base. And the study by Cameron and his colleagues $(1987 \mathrm{a} ; 1987 \mathrm{~b})$ of colleges and universities confirmed that reduction in budgets is associated with greater conflict among members. Further, loss of funds and funding sources can be construed as a sign of failure, and literature on group dynamics consistently indicates that cohesiveness decreases following failure at a group task (Shaw, 1976; Zander, 1979).

In sum, this study assessed the relationship between financial adversity and restriction in information processing (i.e., rigid use of existing procedures), constriction of control (i.e., less participative decision making), conservation of resources (i.e., work force reduction), and competition among members. This provided a partial test of Staw, Sandelands, and Dutton's (1981:516) model of organizational response to threat. Thus, we propose:

Hypothesis 1: Organizations that experience funding decreases will have more rigid use of existing procedures, less participative decision making, more work force reduction, and more competition than organizations that have funding increases.

Hypothesis 2: Organizations that have a decreasing number of funding sources will have more rigid use of existing procedures, less participative decision making, more work force reduction, and more competition than organizations that have increasing numbers of funding sources.

These two hypotheses were tested in a national random sample of drug abuse treatment organizations.

\section{Methods}

\section{Participating Organizations and Individuals}

The present study draws data from drug-abuse treatment organizations that participated in a national study of drug-abuse treatment services (D'Aunno \& Price, 1986). The sample of organizations for the national study $(N=180)$ was ran- 
domly drawn from the total population of outpatient drug abuse treatment organizations in the United States in $1984(N=1,489)$.

These organizations have several distinctive characteristics. First, they depend on state and federal funds for more than $50 \%$ of their budgets. Second, they employ a mix of professional (e.g., psychologists, social workers) and non-professional staff members (e.g., former drug addicts). Third, though the organizations offer a variety of services, most clients receive diagnoses, individual and group therapy, and information and referral services. The majority are licensed by state or regional agencies. Finally, they offer only outpatient services; the sample includes no residential facilities.

The top manager of each of the 180 sample organizations was asked to complete a phone survey concerning the organization's finances, personnel, and clients; 166 organizations agreed to participate, for a response rate of $92 \%$. The managers and all salaried drug-abuse counselors from each organization also were asked to complete mail questionnaires about the organization's structure and their own job characteristics. Of the 166 organizations that completed phone surveys, 80 , or $48 \%$, returned at least two completed mail questionnaires. Because 256 out of 487 respondents returned questionnaires, the average response rate for each participating organization on this questionnaire was $52.6 \%$.

After we accounted for missing data on all variables used here from both the phone surveys and mail questionnaires, 80 organizations remained in the sample. Of these, however, 8 had budget increases between 1981 and 1984 of greater than $300 \%$. Due to their extreme scores, these outliers were omitted from further analyses. ${ }^{3}$ Thus, the study sample consists of 72 organizations.

Analyses were conducted to determine if there were significant differences between the larger study sample of 166 organizations and our sub-sample of 72 organizations. No significant differences were observed in the variables used to stratify the population and to select the sample, which included geographic location (inner city, other urban, suburban, rural), type of services offered (alcohol abuse, drug abuse, or both), and ownership by a parent organization. Further, no significant differences were observed between the larger sample and our subsample in other variables examined, including director tenure and director experience.

\section{Research Design}

This study uses a cross-sectional research design with four control variables (discussed below) included in statistical analyses in order to take alternative explanations into account. Two other features of the research design are important to note. First, the study takes advantage of a major change in funding for drug abuse treatment services. That is, beginning in 1981 and continuing until only recently, total federal and state expenditures for drug abuse treatment services decreased (Weisner \& Room, 1984). As a result, many treatment organizations faced financial adversity.

\footnotetext{
${ }^{3}$ We also conducted analyses in which the outliers (i.e., organizations that experienced greater than 300 percent increases in their budgets from 1981 to 1984) were retained and in which their scores were capped at $300 \%$. The results from these analyses are similar to the results reported in this paper.
} 
Second, the study sample includes organizations that are independent $(N=40)$ and organizations that are owned by a parent $(N=32)$. It is possible that independent drug abuse treatment organizations are more threatened by financial adversity than organizations that have parents that can buffer them from environmental threats (Thompson, 1967). By including organizations with and without parents in the sample, this study examined the role of parent organizations in responses to financial adversity.

\section{Data Sources and Measures}

This study relies on data from three sources: first, mail surveys conducted in 1981 by the National Institute on Drug Abuse (NIDA) and the National Institute on Mental Health (NIMH) of all drug abuse treatment organizations in the United States; second, the telephone survey described above of a randomly selected subset of all treatment organizations conducted at The University of Michigan's Institute for Social Research in June, July, and August of 1984; third, the mail questionnaire described above of the same sample of organizations conducted in October and November of 1984. Data from these sources were used to build the measures described below. Table 1 shows descriptive statistics for all the measures, including mean scores, standard deviations, and intercorrelations.

Measures of financial adversity. Two measures of financial adversity are used in this study: (a) percentage of net change in total budget, 1981 to 1984; and (b) percentage of net change in number of funding sources, 1983 to 1984 . The measures of change in total budget and number of funding sources range on a continuum from negative to positive scores; negative scores indicate greater financial adversity. Negative scores indicate decreases in total budgets and number of funding sources. Positive scores indicate less financial adversity; that is, total budgets and number of funding sources are increasing.

Table 1

Means, Standard Deviations, and Intercorrelations for All Variables

\begin{tabular}{|c|c|c|c|c|c|c|c|c|c|c|c|c|}
\hline & Variables & $M$ & $S D$ & 1 & 2 & 3 & 4 & 5 & 6 & 7 & 8 & 9 \\
\hline 1. & $\begin{array}{l}\text { Net change in } \\
\text { total budget }\end{array}$ & & & & & & & & & & & \\
\hline \multirow[t]{2}{*}{2.} & $\begin{array}{l}\text { ('81-'84) } \\
\text { Net change in } \\
\# \text { of funding }\end{array}$ & -14.8 & 60.6 & & & & & & & & & \\
\hline & sources ('83-'84) & -3.2 & 26.4 & .01 & & & & & & & & \\
\hline \multirow[t]{2}{*}{3.} & Parent & & & & & & & & & & & \\
\hline & Organization & .53 & .50 & -.23 & .11 & & & & & & & \\
\hline \multirow[t]{2}{*}{4.} & Organization & & & & & & & & & & & \\
\hline & Age & 10.1 & 3.8 & .07 & -.10 & -.12 & & & & & & \\
\hline $\begin{array}{l}5 . \\
6 .\end{array}$ & FTEs, 1984 & 7.1 & 4.0 & .16 & .05 & -.19 & .13 & & & & & \\
\hline 6. & Director & & & & & & & & & & & \\
\hline 7. & $\begin{array}{l}\text { Experience } \\
\text { Participation }\end{array}$ & 18.9 & 7.1 & -.16 & -.18 & .10 & .37 & $\begin{array}{r}-.12 \\
23\end{array}$ & -.12 & & & \\
\hline \multirow[t]{2}{*}{8.} & $\begin{array}{l}\text { Participation } \\
\text { Rigid Use of }\end{array}$ & 3.62 & .71 & .10 & .26 & -.16 & -.07 & .23 & & & & \\
\hline & Procedures & 2.00 & .47 & -.25 & -.05 & .27 & -.12 & .18 & -.04 & .38 & & \\
\hline \multirow[t]{2}{*}{9.} & Change in & & & & & & & & & & & \\
\hline & Work Force Size & -20.4 & 45.7 & .15 & .28 & -.06 & -.07 & .07 & .01 & -.07 & -.13 & \\
\hline & Competition & 1.82 & .60 & -.20 & -.13 & .11 & -.09 & .09 & -.14 & .27 & .37 & .03 \\
\hline
\end{tabular}


The measure of change in funds (change in total budget, 1981 to 1984) was constructed by subtracting the total operating budget for each organization for fiscal year 1980-81 from fiscal year 1983-84, and then dividing by the 1980-81 fiscal year budget figure. This computation produces a score for each organization that indicates the percentage change in its total operating budget over a 3-year interval. Further, the effect of inflation on the size of operating budgets was controlled using the Consumer Price Index to adjust budget figures. We selected the 1981-1984 interval because it has the advantage of covering a 3-year period in which reduced external funding began to result in financial adversity for many organizations. Of the 72 sample organizations, 37 had a decrease in total operating budgets from 1981 to 1984 and 35 had budget increases.

The measure of change in number of funding sources (change in \# of funding sources, 1983 to 1984) was constructed in the same manner as the measure of decrease in funds. We subtracted the total number of funding sources for each organization for fiscal year 1982-1983 from fiscal year 1983-1984, and then divided by the 1982-83 number of sources. ${ }^{4} \mathrm{~A}$ "funding source" was defined as a group or organization that reimburses or donates funds to a treatment organization. Examples include insurance companies, state agencies, and the United Way. Thirty-one organizations had a net loss of funding sources; 31 had no change in number of sources, and 10 had a net increase in number of sources.

Organizational response measures. Table 1 presents descriptive statistics for the four measures of organizational responses to financial adversity used here: participative decision making, rigid use of existing procedures, work force reduction, and competition.

The measures of participative decision making, rigid use of existing procedures, and competition among members were derived from the 1984 mail questionnaire. Individual scores from the mail questionnaire were aggregated to measure these organizational characteristics. To check the validity of this approach, we first subjected each item in the participative decision making, rigid use of existing procedures and competition indices to a one-way analysis of variance to determine the extent of agreement in the responses of organization members. An item was included in these indices only if the between-organization variance was greater than the within-organization variance $(p<.05$ for the obtained $F$-ratio) and there was significant agreement of responses within organizations as indicated by the eta-squared statistic (when eta-squared $>.35$ ). This analysis provides evidence for the validity of aggregating individual responses to measure organizational characteristics (Rousseau, 1985).

The measure of participation in decision making was adopted from the Survey of Organizations (1980). Respondents indicated the extent to which managers "provide subordinates with information about decisions in advance," "ask for opinions and ideas from subordinates," "meet with subordinates, present problems that must be solved, and work with them to find solutions." We used a 5point Likert scale. High scores on this index indicate more participation. These items were factor analyzed along with other items concerning organizational re-

\footnotetext{
${ }^{4}$ Unfortunately, data could not be obtained for this measure prior to 1983; thus, this measure does not cover the same time period as the measure of decreases in total budget.
} 
sponses to adversity; the three participation items load highly on one factor (between .77 and .86) and are well differentiated from items that load highly on other factors. Cronbach's alpha is .92 .

The measure of rigid use of existing procedures was also adopted from the Survey of Organizations. Respondents indicated the extent to which "you get endlessly referred from person to person," "you go through a lot of 'red tape' to get things done," and "you get hemmed in by long-standing unit rules and regulations that no one seems able to explain." We used a 5-point Likert scale; high scores on this index indicate more rigid use of existing procedures. Factor analysis showed that the three items loaded highly on one factor (between .60 and .83) and were well differentiated from items loading highly on other factors. Cronbach's alpha is .78.

The measure of change in work force size was constructed for each organization by subtracting total full-time equivalents (FTEs) in 1983 from FTEs in 1984, and dividing the result by the number of FTEs in 1983. This computation produces a score for the percentage of net change in total number of FTEs in each organization for a 1-year interval. Positive scores indicate increases in work force size and negative scores indicate decreases in work force size.

The measure of competition among members was adapted from Van de Ven and Ferry (1980). Respondents used 5-point Likert scales to assess the extent to which members "try to get ahead at the expense of others" and "compete with each other with regard to their work". The two items loaded .78 and .73 on one factor. Cronbach's alpha is .89 . High scores indicate higher levels of competition among organization members.

Control variables. Four other variables were included in the analyses to control for their possible effects on organization structure. First, much research suggests that organizational size is associated with greater formalization and standardization (Scott, 1987). We controlled for the effects of organizational size with a measure of the organization's total number of full-time equivalents (FTEs) in 1984.

Second, research by Pugh, Hickson, Hinings, and Turner (1969) indicated that organizations with a parent were more likely to use centralized rather than participative decision making. Structures of dependent organizations also may be influenced by parent organizations to the extent that they adopt procedures used by the parent. Further, as noted above, parent organizations can buffer firms from environmental threats. Many drug treatment organizations are owned by hospitals or community mental health centers. Thus, we included the presence of a parent organization as a control variable. In the 1984 phone survey, directors reported if their organization was owned by a larger organization (yes $=0$, no $=1$ ).

Third, as organizations age, they tend to become formalized and develop routine procedures (Stinchcombe, 1965). As a result, the effects of organizational age could be confounded with the effects of financial adversity. Organizational age was measured in the 1984 phone survey. Finally, older, more experienced directors of organizations and younger, less experienced directors could respond differently to financial adversity. Older directors may have more experience in dealing with such adversity and thus respond less rigidly than younger directors. We developed a two-item measure of director experience that combined the number 
of years directors had been employed by their organizations and the number of years they had been in the drug abuse treatment field. Cronbach's alpha is .68.

\section{Data Analyses}

Recent research on changes in organizational financial status has used analysis of variance (ANOVA) to compare declining, stable, and growing organizations to one another (e.g., Cameron et al., 1987a; 1987b). In the present study, however, we find two related disadvantages with the use of ANOVA and have used multiple regression to test the hypotheses outlined earlier. The first disadvantage of ANOVA is that one must use somewhat arbitrary cut-off points to distinguish organizations facing financial adversity from non-threatened organizations. For example, how much loss of revenue should an organization experience to be considered "threatened" $-10 \%$ or $15 \%$ ?

A related disadvantage of ANOVA is that continuous or interval level data are transformed to categorical data, entailing a loss in the statistical power to detect differences that may exist between organizations with different numbers of personnel or operating budgets. The use of multiple regression with predictor variables on continuous interval scales avoids these two disadvantages of ANOVA.

It is also important to note that previous conceptual and empirical work (e.g., Cameron et al., 1987a; Freeman \& Hannan, 1975) suggests that organizational growth and decline are not symmetrical processes. For example, Freeman and Hannan (1975) found that the administrative component increases with organization size during periods of growth but that in periods of decline, it does not decrease as fast as the rest of the organization.

Simple linear regression would fail to capture such non-linear, asymmetric relations in the data. As a result, we conducted extensive analyses to search for such relationships in the data using both regression and analysis of variance. First, we used curvilinear regression analyses with polynomial regression equations (Kerlinger \& Pedhazur, 1973) to model non-linear relations between increases and decreases in budget size and number of funding sources and the dependent variables. Second, we also conducted extensive ANOVA analyses to test for non-linear, asymmetric relations in the data. In the ANOVA analyses, the sample was divided first into three groups (increase, stable, decrease) and then into five (much increase, increase, stable, decrease, much decrease). Results from both the curvilinear regression and ANOVA analyses showed no significant non-linear relations between the predictor and dependent variables. Thus the use of linear multiple regression to analyze changes in budget size and number of funding sources is justified in this study.

\section{Results}

Table 2 presents results from multiple regression analyses of the relationships between financial adversity and organizational responses. The control variables were entered in the regression equations simultaneously with the measures of financial adversity.

Hypothesis 1 was that organizations that experience funding decreases will have less participative decision making, rigid use of existing procedures, more 
Table 2

Results of Regression Analyses of the Relationships between Financial Adversity and Organizational Responses $(N=72)^{\mathrm{a}, \mathrm{b}}$

\begin{tabular}{lcccc}
\hline \multicolumn{5}{c}{ Measures of Organizational Responses } \\
$\begin{array}{l}\text { Predictor } \\
\text { Variables }\end{array}$ & $\begin{array}{c}\text { Participative } \\
\text { Decision Making }\end{array}$ & $\begin{array}{c}\text { Rigid Use of } \\
\text { Procedures }\end{array}$ & $\begin{array}{c}\text { Change in } \\
\text { Work Force Size }\end{array}$ & Competition \\
\hline $\begin{array}{l}\text { Net change in } \\
\text { total budget }\end{array}$ & & & & \\
('81-'84) & .05 & $-.24 * *$ & $.17^{* *}$ & $-.23^{* *}$ \\
$\begin{array}{l}\text { Net change in } \\
\text { \# of funding }\end{array}$ & & & & \\
sources ('83-'84) & $.27^{* *}$ & -.12 & $.30^{* * *}$ & $-.20^{* *}$ \\
$\begin{array}{l}\text { FTEs, 1984 } \\
\text { Parent }\end{array}$ & $.19 *$ & $.29 * * *$ & .14 \\
$\begin{array}{l}\text { Organization } \\
\text { Organization Age }\end{array}$ & $-.16^{*}$ & $.28^{* * *}$ & -.13 & .12 \\
Director & -.09 & -.09 & -.09 & -.02 \\
Experience & -.01 & -.05 & .09 & $-.19 *$ \\
\hline$R^{2}$ & .15 & .20 & .30 & .13 \\
$F$-Ratio & $1.86^{* *}$ & $2.70^{* * *}$ & $1.54^{*}$ & $1.59^{*}$ \\
\hline
\end{tabular}

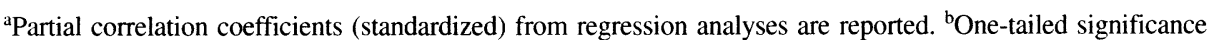
tests are used. ${ }^{~}$ Predictor variables are scored so that negative scores indicate decreases in budget and number of funding sources and positive scores indicate increases; for the dependent variables, higher scores indicate more participation, rigid use of procedures, and more competition; negative scores indicate work force reduction. ${ }^{*} p<.10 . * * p<.05 . * * * p<.01$.

work force reduction and more competition than organizations that have funding increases. The results generally support this hypothesis. Organizations that had budget decreases from 1981 to 1984 had more rigid use of existing procedures, work force reduction, and more competition among members than organizations with increasing budgets.

Hypothesis 2 was that organizations that have decreasing numbers of funding sources will have less participative decision making, more rigid use of existing procedures, more work force reduction and more competition among members than organizations with increasing numbers of funding sources. The results generally support this hypothesis. Organizations that had decreasing numbers of funding sources from 1983 to 1984 , had less participative decision making, more work force reduction, and more competition among members than organizations with an increasing number of funding sources.

Table 2 also indicates that some control variables were significant predictors of organizational responses to financial adversity. Organizations with more employees in 1984 had more participative decision making and more rigid use of existing procedures. Organizations with parents had less participative decision making and more rigid use of existing procedures. Finally, organizations with more experienced directors had less competition among members.

\section{Discussion}

The results of this study of 72 drug abuse treatment organizations tended to support the model of organizational response to threat. The proportion of Beta 
weights confirming our hypotheses (6 of 8 ), although well above chance levels, suggests that this research did not support the model as consistently as might be expected given the arguments posed by Staw and his colleagues (1981), and in recent conceptual work focusing specifically on financial threats (Sutton \& D'Aunno, 1989). Moreover, the magnitudes of these significant relationships are modest. On the whole, however, the results of this research are consistent with the outcomes predicted by the threat rigidity thesis.

First, rigid use of existing procedures was observed in organizations that faced decreasing total budgets from 1981 to 1984 . Rigid use of procedures is a means through which restriction of information processing can occur, particularly reliance on prior knowledge. Second, less participation in decision making was observed in organizations that had a decreasing number of funding sources. Staw and his colleagues propose that limiting participation in decision making is a means through which constriction of control occurs.

Third, their model proposes that conservation of resources may occur in response to financial adversity and that such conservation may be manifested in various cost-cutting measures. Our results indicate that organizations with decreasing budgets and decreasing numbers of funding sources had more work force reduction. Work force reductions are a prominent way to cut costs in laborintensive organizations such as those in this study. Fourth, more competition among organization members was observed in organizations that had decreasing budgets and decreasing numbers of funding sources. We proposed that competition is a rigid response to adversity in that it is likely to reduce cooperation and adaptive collective action.

These results should be viewed with some caution, however, because of the limits of the research. This study considered only drug-abuse treatment organizations. These tend to be small organizations, with a mean of 7.1 FTEs. They also use ambiguous technologies because there is relatively limited knowledge about how to treat drug-and alcohol-abuse problems. Thus, it may be inappropriate to extend the findings from this research to other kinds of organizations.

Nonetheless, despite limitations, this study suggests worthwhile paths for future research. First, though we found a significant relationship between decreasing numbers of funding sources and less participative decision making, no relationship was observed between decreasing budget levels (1981 to 1984) and participative decision making. This is surprising, especially because Staw and his colleagues, in reviewing the literature on organizational threat, point out that "centralization is the most widely acknowledged aspect of the mechanistic shift" (514). The lack of relationship between centralization and decreasing budgets was also evident in two different analyses of the data that Cameron and his colleagues $(1987 a ; 1987 b)$ gathered about colleges and universities. Perhaps this pattern is emerging because decreasing budget levels threaten lower-level employees more than leaders, as Cameron and his colleagues (1987a) proposed.

Second, anxiety and arousal are the proposed means through which threat provokes rigidity in structures. The power of these intervening variables is implied by the individual-level research reviewed by Staw and his colleagues, and by Gladstein and Reilly's (1985) finding that tension was higher among members in 
threatened groups. More complete tests of the model of organizational response to threat should measure these psychological states, and examine whether they are the crucial means through which threat brings about rigidities.

Third, despite the negative connotations associated with the word "rigidity," Staw and his colleagues (1981) point out that restriction in information processing, constriction of control, and conservation of resources are not necessarily maladaptive responses. In the case of financial threats, the adaptiveness of rigidity is contingent on whether such adversity signals a fundamental shift in resources, or if the threat signals a temporary or modest perturbation in an essentially supportive environment. If a fundamental shift occurs, then rigid responses will hamper the ability of the firm to develop needed novel responses. But if the environment remains supportive, then a strategy of relying on existing knowledge, reducing costs, and centralizing so that such changes can be made quickly, is likely to be adaptive for weathering the storm.

We believe that rigid responses by these drug abuse treatment organizations are likely to be adaptive. Threats to their financial circumstances were probably indicative of short-term changes in state economies and the entrance of new, private sector organizations into the market rather than a fundamental shift. In the long term, the need and demand for drug abuse treatment services will continue, and a variety of funding sources will likely be pressured to allocate increased resources.

Finally, Ford and Bacus (1987) assert that decision-makers' interpretations of performance downturns play an important role in determining the extent and kind of their strategic and tactical responses. Thus, the variance that threat did not explain in rigidity in this study may have occurred -in part- because some leaders convinced themselves, and engaged in symbolic actions to convince others, that large financial threats were a temporary condition that required no changes in structures. Or, conversely, a small financial threat, perhaps occurring for the first time in organizational history, may have caused decision-makers in other organizations to construe that they faced profound negative consequences, and to communicate their fears to others. The result may have been more pronounced organizational rigidity. In short, future research may reveal that managerial interpretations and sense-making by other employees moderate the relationship between organizational threat and rigidity.

\section{References}

Cameron, K. S., Kim, M. U., \& Whetten, D. A. 1987a. Organizational effects of decline and turbulence. Administrative Science Quarterly, 32: 222-241.

Cameron, K. S., Whetten D. A., \& Kim, M. U. 1987b. Organizational dysfunctions of decline. Academy of Management Journal, 30: 126-138.

D’Aunno, T. \& Price, R. P. 1986. Linked systems: Drug abuse and mental health services. In W. Richard Scott \& Bruce L. Black (Eds.), The organization of mental health services: 277-307. Beverly Hills, CA: Sage.

Foa, U. 1971. Interpersonal and economic resources. Science, 171: 345-351.

Ford, J. D., \& Baucus, D. A. 1987. Organizational adaptation to performance downturns: An interpretation-based perspective. Academy of Management Review, 12: 366-380.

Freeman, J. H., \& Hannan, M. T. 1975. Growth and decline processes in organizations. American Sociological Review, 40: 215-228.

Gladstein, D. L., \& Reilly, N. P. 1985. Group decision making under threat: The tycoon game. Academy of Management Journal, 28: 613-627. 
Hambrick, D. C., \& Schecter, S. M. 1983. Turnaround strategies for mature industrial-product environments. Academy of Management Journal, 26: 231-248.

Hirschhorn, L., \& Associates. 1983. Cutting back: Retrenchment and redevelopment in human and community services. San Francisco, CA: Jossey-Bass.

Jacobs, D. 1974. Dependency and vulnerability: An exchange approach to the control of organizations. Administrative Science Quarterly, 19: 45-59.

Janis, I. L. 1982. Groupthink (2nd ed.). Boston: Houghton Mifflin.

Kerlinger, F.N., \& Pedhazur, E.J. 1973. Multiple regression in behavioral research. NY: Holt, Rinehart \& Winston.

Meindl, J. R., Ehrlich S. B., \& Dukerich, J. M. 1985. The romance of leadership. Administrative Science Quarterly, 30: 78-102.

Nystrom, P. C., \& Starbuck, W. H. 1984. To avoid organizational crises, unlearn. Organizational Dynamics, 12: 53-65.

Perry, L. T. 1986. Least-cost alternatives to layoffs in declining industries. Organizational Dynamics, 12: 48-61.

Pfeffer, J., \& Leblebici, H. 1973. The effects of competition on some dimensions of organizational structure. Social Forces, 52: 268-279.

Pfeffer, J., \& Salancik, G. R. 1978. The external control of organizations: A resource dependence perspective. New York, NY: Harper \& Row.

Pugh, D. S., Hickson, D. J., Hinings, C. R., \& Turner, C. 1969. The context of organizational structures. Administrative Science Quarterly, 14: 91-114.

Rousseau, D. M. 1985. Issues of level in organizational research: Multi-level and cross-level perspectives. In Larry L. Cummings \& Barry M. Staw (Eds.), Research in organizational behavior, 7:1-37. Greenwich, CT: JAI Press.

Rúbin, I. S. 1977. Universities in stress: Decision making under conditions of reduced resources. Social Science Quarterly, 58: 242-254.

Scott, W. R. 1987. Organizations: Rational, natural, and open systems (2nd ed.). Englewood Cliffs, NJ: Prentice-Hall.

Shaw, M. E. 1976. Group dynamics (2nd ed.). New York: McGraw-Hill.

Starbuck, W. H., Greve A., \& Hedberg, B. L. T. 1978. Responding to crises. Journal of Business Administration, 9: 111-137.

Staw, B. M., Sandelands L. E., \& Dutton, J. E. 1981. Threat-rigidity effects in organizational behavior: A multilevel analysis. Administrative Science Quarterly, 26: 501-524.

Stinchcombe, A. L. 1965. Organizations and social structure. In James G. March (Ed.), Handbook of organizations: 142-193. Chicago: Rand-McNally.

Survey of Organizations. 1980. Ann Arbor, MI: The University of Michigan and Rensis Likert Associates, Inc.

Sutton, R. I., Eisenhardt K. M., \& Jucker, J. V. 1986. Managing organizational decline: Lessons from Atari. Organizational Dynamics, 14: 17-29.

Sutton, R. I., \& D'Aunno, T. 1989. Decreasing organizational size: Untangling the effects of money and people. Academy of Management Review, 14: 194-212.

Thomas, K. 1976. Conflict and conflict management. In M.D. Dunnette (Ed.) Handbook of industrial and organizational psychology: 889-936. Chicago: Rand McNally.

Thompson, J. D. 1967. Organizations in action: New York: McGraw-Hill.

Van de Ven, A. H., \& Ferry, D. J. 1980. Measuring and assessing organizations. New York: John Wiley \& Sons.

Warren, D. L. 1984. Managing in crisis: Nine principles for successful transition. In J. R. Kimberly \& R. E. Quinn (Eds.), Organizational effectiveness: A comparison of multiple models: 71-93. New York: Academic Press.

Weisner, C., \& Room, R. 1984. Financing and ideology in alcohol treatment. Social Problems, 32: 167-184.

Whetten, D. A. 1980a. Organizational decline: A neglected topic in organizational behavior. Academy of Management Review, 5: 577-588.

Whetten, D. A. 1980b. Organizational decline: Sources, responses, and effects. In John Kimberly \& Robert Miles (Eds.), Organizational life cycles: 342-374. San Francisco, CA: Jossey-Bass. 
Zajonc, R. B. 1965. Social facilitation. Science, 149: 269-274.

Zander, A. 1979. The psychology of group process. Annual review of psychology. Palo Alto, CA: Annual Reviews. 